\title{
STRATEGI PENGEMBANGAN \\ KOMPETENSI MANAJERIAL APARATUR SIPIL NEGARA (ASN) MELALUI PENDIDIKAN DAN PELATIHAN DI KABUPATEN NAGANRAYA PROVINSI ACEH
}

\author{
Oleh \\ Rizki Hidayatullah', \\ Etin Indrayani ${ }^{2}$, Dadang Suwanda ${ }^{3}$ \\ 1) Badan Kepegawaian dan Pengembangan Sumber Daya Manusia Kabupaten Naganraya \\ Program Magister Terapan Studi Pemerintahan Institut Pemerintahan Dalam Negeri \\ rizkihidayatullah2206@gmail.com \\ 2,3) Institut Pemerintahan Dalam Negeri
}

\begin{abstract}
$T$ he lack of competency development for ASN Naganraya Regency both from the aspects of education and training. The purpose of this study was to analyze the development of ASN Managerial competence, to analyze internal and external factors and to analyze the ASN Managerial Competency development strategy in Naganraya Regency.This research uses a qualitative method with a descriptive approach, and uses the theory of developing human resource competencies through education and training according to Busro (2018: 206) which is measured by opportunities and opportunities to attend education and opportunities to participate in training.

The results showed that the development of ASN managerial competence through education and training in Naganraya Regency has not been carried out optimally, because the opportunities to participate in education and training provided are very few, scholarships opportunities outside the $A P B D$ are also underutilized by both the Regional Government and ASN. Internal factors 1) Regulations and regulations, 2) Vision and mission of the Regent of Naganraya, 3) Authority, 4) There is no Perbup regarding study assignments and study permits, 5) Budget limitations, and external factors 1) Program There is a scholarships outside the Naganraya Regional Budget, 2) The existence of high schools in Naganraya Regency, 3) Political Intervention, 4) Mindset There are ASN who have considered their learning tasks to be politicized. Strategy for developing ASN managerial competence through education and training 1) Arranging a Perbup as a reference for study assignments and study permits, both budgets that use the APBD and outside the APBD, 2) Forming a task force to accelerate the development of ASN managerial competencies in implementing scholarships for study assignments outside the APBD, 3) Building cooperation with high schools in Naganraya Regency, 4) Increase socialization, transparency and transparency as well as service certainty, 5) Encourage ASN for study permits in high schools in Naganraya Regency, 6) Utilize and facilitate ASN in participating in scholarships outside the APBD, 7) Building a joint commitment to work professionally. As for suggestions 1) The need to increase opportunities for education and training as well as to take full advantage of scholarships opportunities outside the APBD, 2) The need to make maximum use of strengths and opportunities, and cover weaknesses and overcome threats, 3) The need to coordinate and improve the quality of personnel services to implement development strategy.
\end{abstract}

Keywords: managerial competency development, education and training, competent ASN 


\section{Abstrak}

$\mathrm{M}$ inimnya pengembangan kompetensi ASN Kabupaten Naganraya baik dari aspek pendidikan maupun pelatihan. Tujuan penelitian ini adalah untuk menganalisis pengembangan kompetensi Manajerial ASN, menganalisis faktor internal dan eksternal serta untuk menganalisis strategi pengembangan Kompetensi Manajerial ASN di Kabupaten Naganraya. Penelitian ini menggunakan metode kualitatif dengan pendekatan deskriptif, dan menggunakan teori pengembangan kompetensi sumber daya manusia melalui pendidikan dan pelatihan menurut Busro (2018: 206) yang diukur dengan kesempatan dan peluang mengikuti pendidikan serta kesempatan mengikuti pelatihan.

Hasil penelitian bahwa pengembangan kompetensi manajerial ASN melalui pendidikan dan pelatihan di Kabupaten Naganraya belum dilakukan secara optimal, dikarenakan kesempatan mengikuti pendidikan dan pelatihan yang disediakan sangat sedikit, peluang beasiswa di luar APBD juga kurang dimanfaatkan dengan baik oleh Pemerintah Daerah maupun ASN. Faktor internal 1) Peraturan perundang-undangan, 2) Visi misi Bupati Naganraya, 3) Kewenangan, 4) Belum adanya Perbup tentang tugas belajar dan izin belajar, 5) Keterbatasan anggaran, dan faktor eksternal 1) Adanya program beasiswa di luar APBD Naganraya, 2) Adanya sekolah tinggi di Kabupaten Naganraya, 3) Intervensi Politik, 4) Adanya mindset ASN yang menganggap tugas belajar di politisasi. Strategi pengembangan kompetensi manajerial ASN melalui pendidikan dan pelatihan 1) Menyusun Perbup sebagai rujukan tugas belajar dan izin belajar baik anggaran yang menggunakan APBD maupun di luar APBD, 2) Membentuk satuan tugas percepatan pengembangan kompetensi manajerial ASN dalam pemanfaatan beasiswa tugas belajar di luar APBD, 3) Membangun kerja sama dengan sekolah tinggi yang ada di Kabupaten Naganraya, 4) Meningkatkan sosialisasi, dan transparansi serta kepastian pelayanan, 5) Mendorong ASN untuk izin belajar di sekolah tinggi yang ada di Kabupaten Naganraya, 6) Memanfaatkan dan memfasilitasi ASN dalam mengikuti beasiswa di luar APBD, 7) Membangun komitmen bersama untuk bekerja secara profesional. Adapun saran 1) Perlunya memperbanyak kesempatan untuk mengikuti pendidikan dan pelatihan serta memanfaatkan peluang beasiswa di luar APBD dengan maksimal, 2) Perlunya memanfaatkan secara maksimal kekuatan dan peluang, dan menutupi kelemahan serta mengatasi ancaman, 3) Perlunya mengoordinasikan, bekerja sama dan meningkatkan kualitas pelayanan kepegawaian untuk melaksanakan strategi pengembangan.

Kata kunci: pengembangan kompetensi manajerial, pendidikan dan pelatihan, ASN berkompeten

\section{PENDAHULUAN}

$\mathrm{M}_{1}$ enurut Peraturan Pemerintah No. 11 Tahun 2017 tentang Manajemen Pegawai Negeri Sipil, Pasal 210 bahwa bentuk pengembangan kompetensi dapat dilakukan melalui Pendidikan dan pelatihan. Lebih lanjut dalam Pasal 211 menyatakan bahwa Pendidikan dilakukan untuk meningkatkan pengetahuan dan keahlian ASN melalui Pendidikan formal.

Kabupaten Naganraya dengan ibu kota Sukamakmur, merupakan salah satu daerah pemekaran dari Kabupaten Aceh Barat
Provinsi Aceh yang dibentuk dengan UndangUndang No. 4 Tahun 2002 dan diresmikan pada 2 Juli 2002 oleh Menteri Dalam Negeri di Jakarta. Pada 2019 Kabupaten Naganraya mendapatkan nilai kategori kurang (C) pada SAKIP (Sistem Akuntabilitas Kinerja Instansi Pemerintah). Dari hal tersebut, maka dinilai perlu mengembangkan Sumber Daya Aparatur Sipil Negara secara terencana, konsisten, dan berkelanjutan demi tersedianya Aparatur Sipil Negara yang profesional untuk meningkatkan kualitas penyelenggaraan pemerintahan daerah. Hal ini sejalan dengan hasil penelitian berupa jurnal yang mengatakan pelaksanaan 
pengembangan kompetensi SDM yang dilakukan secara berkesinambungan diharapkan akan menciptakan kinerja pegawai serta kinerja organisasi yang meningkat sehingga dapat meningkatkan kualitas pelayanan publik oleh instansi pemerintah.

Pengembangan kompetensi sumber daya aparatur dapat dilihat dari tiga kompetensi, S.E.bagaimana dalam Undang-Undang No. 5 Tahun 2014 Pasal 69 ayat (3) berbunyi Kompetensi sebagaimana dimaksud ayat (1) meliputi:

1. kompetensi teknis yang diukur dari tingkat dan spesialisasi pendidikan, pelatihan teknis fungsional, dan pengalaman bekerja secara teknis;

2. kompetensi manajerial yang diukur dari tingkat pendidikan, pelatihan struktural atau manajemen, dan pengalaman kepemimpinan; dan

3. kompetensi sosial kultural yang diukur dari pengalaman kerja berkaitan dengan masyarakat majemuk dalam hal agama, suku, dan budaya sehingga memiliki wawasan kebangsaan.

Dari ketiga kompetensi tersebut, kompetensi manajerial merupakan faktor utama dalam menggerakkan roda pemerintahan untuk mencapai pemerintahan yang berkualitas.

Di samping itu peningkatan kompetensi juga merupakan visi dan misi Bupati Kabupaten Naganraya, yaitu terdapat pada misi kelima bahwa "Meningkatkan kualitas sumber daya manusia (SDM) dengan memberikan dukungan maksimal terhadap pendidikan formal dan informal". Terkait kompetensi manajerial sumber daya aparatur Kabupaten Naganraya dilihat dari tingkat pendidikan dan pelatihan masih banyak yang belum sarjana dan belum mengikuti diklat, S.E.bagaimana data tabel berikut.
Tabel 1 Rekapan Tingkat Pendidikan PNS Kabupaten Naganraya Tahun 2019

\begin{tabular}{clrr}
\hline No. & \multicolumn{1}{c}{$\begin{array}{c}\text { Tingkat } \\
\text { Pendidikan }\end{array}$} & $\begin{array}{c}\text { Jumlah } \\
\text { (Orang) }\end{array}$ & $\begin{array}{c}\text { Presen- } \\
\text { tase }\end{array}$ \\
\hline 1. & SLTP & 112 & $3,05 \%$ \\
2. & SLTA/Sederajat & 1009 & $27,50 \%$ \\
3. & Diploma I & 5 & $0,10 \%$ \\
4. & Diploma II & 21 & $0,50 \%$ \\
5. & Diploma III & 201 & $5,40 \%$ \\
6. & Diploma IV & 324 & $8,80 \%$ \\
7. & Strata 1 & 1982 & $54 \%$ \\
8. & Strata 2 & 9 & $0,20 \%$ \\
9. & Strata 3 & 1 & $0,02 \%$ \\
\hline & TOTAL & 3.664 & 100,00 \\
\hline
\end{tabular}

Sumber: BKPSDM Naganraya 2019

Berdasarkan tabel di atas diketahui bahwa dari jumlah PNS lingkup Kabupaten Naganraya sebanyak 3.664 orang, tingkat pendidikan SLTP sebanyak 112 jiwa (30,55\%), tingkat pendidikan SLTA sebanyak 1009 jiwa (27,50\%), Diploma I sebanyak 5 jiwa $(0,10 \%)$, Diploma II sebanyak 21 jiwa (0,50\%), Diploma III sebanyak 201 jiwa (5,40\%), Diploma IV sebanyak 324 jiwa (8,80\%), tingkat pendidikan Strata I sebanyak 1982 jiwa (54\%), tingkat pendidikan Strata II sebanyak $9(0,20 \%)$, dan tingkat pendidikan Strata III sebanyak $1(0,02 \%)$.

Dari data di atas dapat dilihat bahwa pendidikan Aparatur Sipil Negara lingkup Kabupaten Naganraya masih harus ditingkatkan ke jenjang yang lebih tinggi mengingat 30,55\% dari jumlah ASN pada Kabupaten Naganraya masih berpendidikan nonsarjana dan berpendidikan rendah untuk menunjang peningkatan kinerja Pemerintah Naganraya khususnya kompetensi manajerial, kemudian sangat sedikitnya ASN yang berpendidikan Magister dengan persentase $0,20 \%$ dari jumlah ASN yang ada.

Dilihat dari aspek diklat, pengembangan kompetensi manajerial pada lingkup Kabupaten Naganraya juga masih kurang dilakukan. Adapun rekapitulasi data yang 
menunjukkan kurangnya pengembangan kompetensi manajerial ASN melalui diklat dapat dilihat pada tabel 2. di bawah ini:

Tabel 2 Rekapitulasi Jumlah ASN Yang Telah Mengikuti Diklatpim Dalam Lingkup Kabupaten Naganraya Dari Tahun 2011 s.d. 2019

\begin{tabular}{cccccc}
\hline \multirow{2}{*}{ No } & Tahun & \multicolumn{3}{c}{ Jenjang Diklat } & Jum- \\
\cline { 3 - 5 } & & PIM & PIM & PIM & lah \\
& & II & III & IV & \\
\hline 1 & 2011 & - & - & 6 & 6 \\
2 & 2013 & - & 1 & 2 & 3 \\
3 & 2014 & - & - & - & - \\
4 & 2015 & - & - & - & - \\
5 & 2016 & 1 & 6 & 7 & 14 \\
6 & 2017 & - & 3 & - & 3 \\
7 & 2018 & - & - & 4 & 4 \\
8 & 2019 & 1 & - & 1 & 2 \\
\hline & Jumlah & 2 & 10 & 20 & 32 \\
\hline
\end{tabular}

Sumber: BKPSDM Naganraya 2019

Berdasarkan tabel di atas dapat dilihat bahwa dari rentan tahun 2011 hingga 2019 hanya 32 ASN pada Kabupaten Naganraya yang mengikuti diklat, S.E.mentara jumlah pejabat struktural pada Kabupaten Naganraya berkisar antara empat ratus pejabat. Hal tersebut menunjukkan masih banyaknya pejabat struktural yang belum mengikuti diklat struktural.

Membahas terkait pendidikan dan pelatihan tentunya tidak terlepas dari roadmap pengembangan kompetensi ASN. Namun pada Kabupaten Naganraya belum ada roadmap dalam menentukan pengembangan, S.E.bagaimana dikatakan oleh Kabid Perencanaan, Pengembangan SDM dan Diklat BKPSDM Kabupaten Naganraya, Efliyanto.

Dari permasalahan di atas, tentunya ini menjadi tanggung jawab Pemerintah Daerah sebagaimana amanat Undang-Undang No. 5 Tahun 2014 tentang Aparatur Sipil Negara Pasal 55 ayat (3) yang berbunyi Manajemen PNS pada instansi daerah dilaksanakan oleh pemerintah daerah sesuai dengan ketentuan peraturan perundang-undangan. Untuk melaksanakan hal tersebut sesuai dengan PP No. 18 Tahun 2016 tentang Perangkat Daerah yang kemudian dijabarkan dalam Qanun Kabupaten Naganraya No. 3 Tahun 2016 tentang Pembentukan dan Susunan Perangkat Daerah Kabupaten Naganraya yang mana di dalamnya tercantum pembentukan Badan Kepegawaian dan Pengembangan Sumber Daya Manusia yang memiliki Tugas dan Fungsi sesuai dengan Perbup Naganraya No. 77 Tahun 2016 bahwasanya pada Pasal 5 menyatakan Badan Kepegawaian dan Pengembangan Sumber Daya Manusia mempunyai tugas membantu Bupati dalam melaksanakan urusan pemerintahan di bidang kepegawaian dan pengembangan sumber daya manusia yang menjadi kewenangan daerah dan tugas pembantuan yang diberikan kepada daerah.

Terkaittugastersebut, Badan Kepegawaian dan Pengembangan Sumber Daya Manusia mengurusi manajemen kepegawaian daerah salah satunya pengembangan kompetensi manajerialASNyang juga merupakanhaksetiap ASN sebagaimana amanat Undang-Undang No. 5 Tahun 2014 Pasal 21 huruf e bahwa PNS berhak memperoleh pengembangan kompetensi.

Di samping itu sesuai dengan amanat Peraturan Presiden Republik Indonesia No. 81 Tahun 2010 tentang Grand Design Reformasi Birokrasi 2010-2025 ditetapkan bahwa reformasi birokrasi merupakan perubahan secara bertahap dalam rangka mencapai visi "mewujudkan pemerintahan kelas dunia". Sumber Daya Manusia Aparatur merupakan komponen utama dalam menuju pemerintahan kelas dunia.Untukmembentuk sumber daya aparatur yang berkelas dunia menuntut keharusan pengembangan kompetensi aparatur berkualitas melalui pendidikan dan pelatihan yang terencana, terarah,dan berkelanjutan.

Oleh karena itu, penelitian ini menjadi penting dilakukan, peneliti menilai bahwa 
kompetensi manajerial aparatur merupakan hal penting yang berdampak terhadap kualitas penyelenggaraan pemerintahan daerah, dan menjadi salah satu Visi Misi dari Bupati Kabupaten Naganraya.

\section{Masalah Penelitian}

Berdasarkan uraian pendahuluan di atas, maka peneliti merumuskan masalah sebagai berikut.

1. Bagaimanakah Pengembangan Kompetensi Manajerial Aparatur Sipil Negara melalui pendidikan dan pelatihan di Kabupaten Naganraya?

2. Apa sajakah faktor internal dan eksternal dalam Pengembangan Kompetensi Manajerial Aparatur Sipil Negara melalui pendidikan dan pelatihan di Kabupaten Naganraya?

3. Bagaimanakah Strategi Pengembangan Kompetensi Manajerial Aparatur Sipil Negara melalui pendidikan dan pelatihan di Kabupaten Naganraya?

\section{Tujuan Penelitian}

Tujuan penelitian ini dirumuskan sebagai berikut.

1. Untuk menganalisis dan mendeskripsikan Pengembangan Kompetensi Manajerial Aparatur Sipil Negara Kabupaten Naganraya.

2. Untuk menganalisis dan mendeskripsikan faktor internal dan eksternal dalam Pengembangan Kompetensi Manajerial Aparatur Sipil Negara Kabupaten Naganraya.

3. Untuk merumuskan strategi Pengembangan Kompetensi Manajerial Aparatur Sipil Negara Kabupaten Naganraya.

\section{KAJIAN PUSTAKA}

\section{Fungsi Pemerintahan}

Rasyid dalam Ndraha (2011: 58) menyatakan bahwa tugas pokok pemerintahan dikelompokkan menjadi 3(tiga) fungsi pemerintahan yang hakiki yaitu pelayanan (service), pemberdayaan (empowerment), dan pembangunan (development).

Fungsi-fungsi manajemen pemerintahan yang dimaksud Ndraha (2011: 159) antara lain sebagai berikut.

1. Perencanaan pemerintahan; dilakukan untuk mengklarifikasi tujuan organisasi dan menyusun langkah-langkah guna mencapai tujuan (tujuan konkret dan terukur) organisasi.

2. Pengorganisasian sumber-sumber pemerintahan; realisasi (implementasi) langkah-langkah tersebut memerlukan sumber daya, baik SDA, SDM, maupun SDB. Sebelum digunakan, sumber daya harus diorganisasikan agar siap pakai.

3. Penggunaan sumber-sumber pemerintahan; dilakukan untuk menggerakkan sumber-sumber pemerintahan agar mendapatkan hasil-hasil yang sudah ditetapkan.

4. Kontrol pemerintahan; dilakukan untuk menjamin kesesuaian antara target pada perencanaan dengan hasil yang diperoleh dari penggunaan sumbersumber pemerintahan tersebut.

\section{Pengembangan Sumber Daya Manusia}

Rachmawati (2008: 3) mengemukakan bahwa Manajemen sumber daya manusia merupakan suatu proses perencanaan, pengorganisasian, pengarahan dan pengawasan kegiatan-kegiatan pengadaan, pengem bangan, pemberian kompensasi, pengintegrasian, pemeliharaan dan pelepasan sumber daya manusia agar tercapai berbagai tujuan individu, organisasi dan masyarakat.

Pengembangan didasarkan pada fakta bahwa seorang aparatur membutuhkan serangkaian pengetahuan, keahlian dan kemampuan yang berkembang supaya bekerja dengan baik dalam melaksanakan 
tugas dan fungsinya selama kariernya. Persiapan karier jangka panjang dari seorang aparatur untuk serangkaian posisi inilah yang dimaksudkan dengan pengembangan aparatur.

Dalam bukunya Veithzal Rivai (2004: 229) mengemukakan tujuan dari pelatihan dan pengembangan adalah:

1) Untuk meningkatkan kuantitas output;

2) Untuk meningkatkan kualitas output;

3) Untuk menurunkan biaya limbah dan perawatan;

4) Untuk menurunkan jumlah dan biaya terjadinya kecelakaan;

5) Untuk menurunkan turnover, ketidakhadiran kerja serta meningkatkan kepuasan kerja;

6) Untuk mencegah timbulnya antipati karyawan.

Menurut Hasibuan (2009: 72), Jenis-jenis Pengembangan secara umum dikelompokkan atas: Pengembangan secara informal dan pengembangan secara Formal.

1. Pengembangan secara Informal yaitu karyawan atas keinginan dan usaha sendiri melatih dan mengembangkan dirinya dengan mempelajari buku-buku literatur yang ada hubungannya dengan pekerjaan atau jabatannya.pengembangan secara informal menunjukkan bahwa karyawan tersebut berkeinginan keras untuk maju dengan cara meningkatkan kemampuan kerjanya.hal ini bermanfaat bagi perusahaan karena prestasi kerja karyawan semakin besar, Di samping efisiensi dan produktivitasnya juga semakin baik.

2. Pengembangan secara Formal yaitu karyawan ditugaskan perusahaan untuk mengikuti pendidikan atau latihan, baik yang dilakukan perusahaan maupun yang dilaksanakan oleh lembagalembaga pendidikan dan pelatihan, pengembangan secara formal dilakukan perusahaan karena tuntutan pekerjaan saat ini maupun masa datang, yang sifatnya nonkarier atau peningkatan karier seorang karyawan.

Gouzali dalam Kadarisman (2013: 5) mengemukakan Pengembangan SDM (Sumber Daya Manusia), merupakan kegiatan yang harus dilaksanakan organisasi, agar pengetahuan (knowledge), kemampuan (ability), dan keterampilan (skill) mereka sesuai dengan tuntutan pekerjaan yang mereka lakukan. Dengan kegiatan pengembangan ini, maka diharapkan dapat memperbaiki dan mengatasi kekurangan dalam melaksanakan pekerjaan dengan lebih baik, S.E.suai dengan perkembangan ilmu dan teknologi yang digunakan organisasi.

Pengembangan sumber daya manusia merupakan unsur yang sangat penting dalam organisasi sebab pegawai merupakan aset yang sangat penting dalam mencapai tujuan organisasi yang telah ditetapkan. Notoatmodjo (2009: 4) mengemukakan bahwa pengembangan sumber daya manusia adalah "suatu proses perencanaan pendidikan, pelatihan dan pengelolaan tenaga atau pegawai untuk mencapai hasil yang optimal".

\section{Pendidikan dan Pelatihan}

Konstruk pendidikan dan pelatihan menurut Busro (2018: 206) diukur dengan indikator:

1. Kesempatan mengikuti pendidikan lanjut;

2. Kesempatan mengikuti diklat;

3. Kesempatan mengikuti TOT/seminar/ workshop/simposium dan sejenisnya.

Dimensi kesempatan mengikuti pendidikan lanjut diukur dari kesempatan mengikuti pendidikan S-2/S-3, (b) peluang mendapatkan beasiswa S-2/S-3. Dimensi kesempatan diklat dari (a) jumlah diklat yang pernah diikuti, (b) jumlah jam diklat yang pernah diikuti. Dimensi kesempatan 


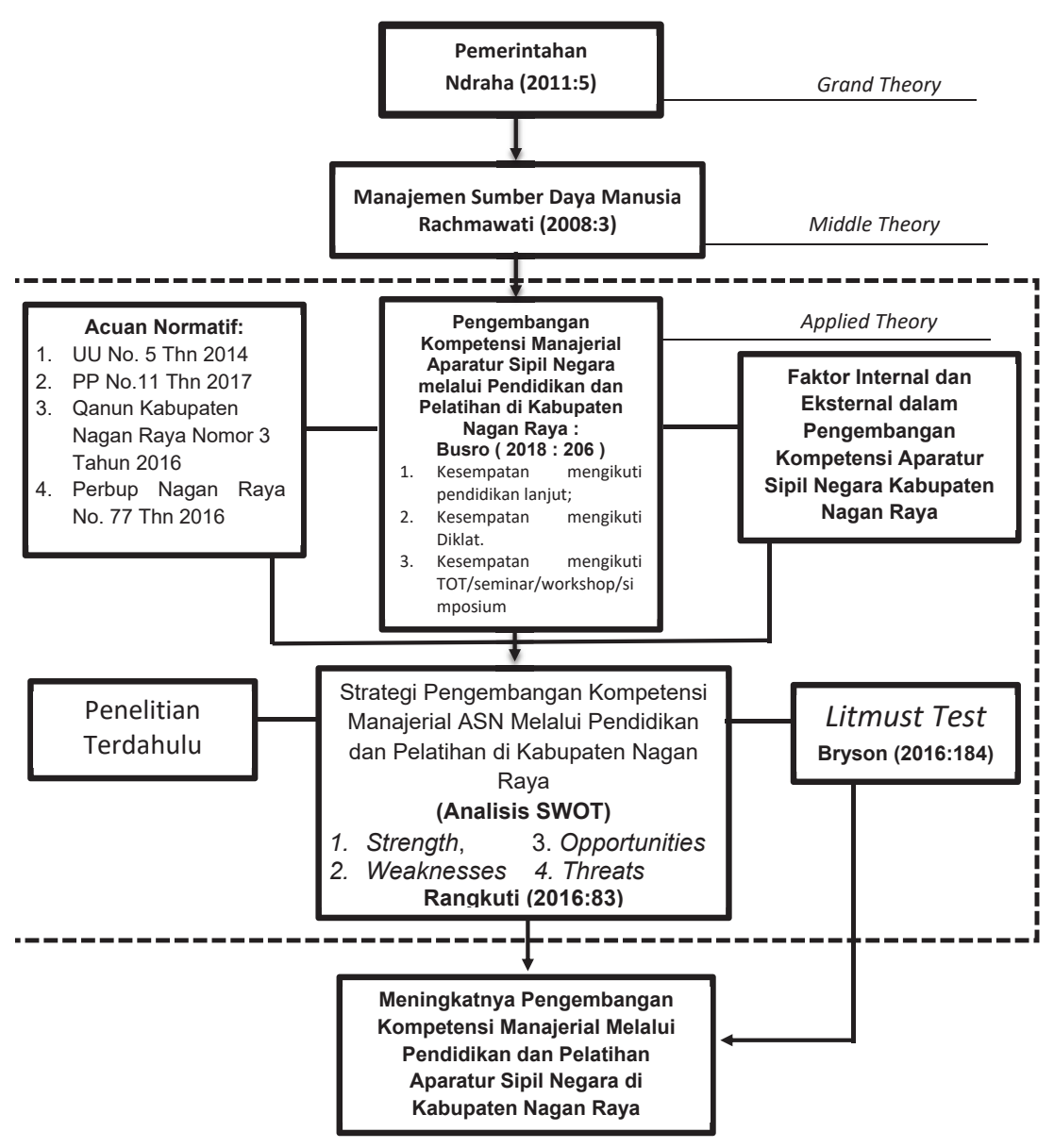

Gambar 1

Kerangka Pemikiran

mengikuti TOT/seminar diukur dari indikator (a) jumlah TOT yang pernah diikuti (b) jumlah jam TOT yang pernah diikuti, dan (c) jumlah seminar dan sejenisnya yang pernah diikuti.

\section{METODE PENELITIAN}

Metode penelitian kualitatif dengan pendekatan deskriptif digunakan dalam penelitian ini, peneliti ingin menggambarkan keadaan di tempat penelitian. Penelitian kualitatif adalah penelitian yang menghasilkan data deskriptif mengenai kata-kata lisan maupun tertulis, dan tingkah laku yang dapat diamati dari orang-orang yang diteliti, Nawawi (2012: 209). Metode penelitian kualitatif adalah metode penelitian yang digunakan untuk meneliti pada kondisi objek yang alamiah (lawannya adalah eksperimen di mana peneliti adalah sebagai instrumen kunci, teknik pengumpulan data dilakukan secara triangulasi (gabungan), analisis data bersifat induktif dan hasil penelitian kualitatif lebih menekankan makna dari pada generalisasi, Sugiyono (2013: 1). Adapun sumber data diperoleh dari tiga sumber yaitu person, place, dan paper. Teknik pengumpulan data dalam penelitian ini dengan wawancara, observasi, dokumentasi, dan teknik analisis data dengan reduksi data (data reduction), penyajian data (data displai), mengambil simpulan/verifikasi data (conclusion:drawing/verification), Creswell (2009: 175). 


\section{Informan dan Cara Menentukannya}

Informan dalam penelitian diambil secara purposive sampling. Berdasarkan teknik purposive sampling, informan dalam penelitian ini adalah sebagai berikut.

Tabel 3 Informan Penelitian

\begin{tabular}{|c|c|c|}
\hline No. & Jabatan & Jumlah \\
\hline 1. & $\begin{array}{l}\text { Kepala BKPSDM Kabupaten } \\
\text { Naganraya } \\
\text { (B. Surya Bakti, S.E.) }\end{array}$ & 1 \\
\hline 2. & $\begin{array}{l}\text { Sekretaris BKPSDM Kabupaten } \\
\text { Naganraya } \\
\text { (Ibu Lies Herlina Agustini, S.E.) }\end{array}$ & 1 \\
\hline 3. & $\begin{array}{l}\text { Kabid } \text { Perencanaan, } \\
\text { Pengembangan SDM dan } \\
\text { Diklat BKPSDM Kabupaten } \\
\text { Naganraya } \\
\text { ( Efliyanto, S.E. M.M.) }\end{array}$ & 1 \\
\hline 4. & $\begin{array}{l}\text { Kasubid Pengembangan Karier } \\
\text { dan SDM BKPSDM Kabupaten } \\
\text { Naganraya } \\
\text { (Ibu Dewi Asnidar, S.E.) }\end{array}$ & 1 \\
\hline 5. & $\begin{array}{l}\text { Kasubid Diklat Jabatan dan } \\
\text { Teknis BKPSDM Kabupaten } \\
\text { Naganraya } \\
\text { (Ibu Nelli Munawar, S.E.) }\end{array}$ & 1 \\
\hline 6. & $\begin{array}{l}\text { ASN Kabupaten Naganraya } \\
\text { ( Chairul Ichsan, S.E.) } \\
\text { ( Sayuti, S.E.) } \\
\text { ( Mungga Ridwan, S.E.) }\end{array}$ & 3 \\
\hline & Total & 8 \\
\hline
\end{tabular}

Sumber: Diolah Peneliti, 2020

\section{HASIL PENELITIAN}

1. Pemerintah Daerah Kabupaten Naganraya telah memberikan kesempatan melalui tugas belajar dan izin belajar, namun pada tugas belajar formasi yang disediakan sangat sedikit, Peraturan Bupati tentang tugas belajar dan izin belajar juga belum ada yang seharusnya itu menjadi dasar hukum dan mekanisme pelaksanaan, belum adanya SOP, tidak adanya transparansi dalam proses penetapan peserta, kurangnya sosialisasi dan keterbatasan anggaran.

2. Peluang beasiswa bagi ASN Kabupaten Naganraya telah disediakan oleh pemerintah daerah dan pemerintah pusat, namun dilihat dari beasiswa yang disediakan oleh pemerintah daerah peluangnya sangat sedikit dan biaya yang disediakan pun juga sedikit. Bahkan beasiswa belum bisa diberikan jika peserta beasiswa sebelumnya belum menyelesaikan pendidikan.

3. Pemerintah Kabupaten Naganraya sudah mengikutkan ASN di setiap jenjang diklat, namun tidak semua jenjang diklat disediakan setiap tahunnya, saat ini hanya menyediakan diklat pim IV, dan masih banyak pejabat eselon yang belum mengikuti diklat yang seharusnya diikuti dikarenakan kekurangan anggaran, terlihat dari tahun 2011 s.d. 2019 hanya 32 ASN yang baru didiklatkan.

\section{SIMPULAN}

1. Pengembangan kompetensi manajerial ASN melalui pendidikan dan pelatihan di Kabupaten Naganraya belum dilakukan secara optimal, dikarenakan kesempatan mengikuti pendidikan dan pelatihan yang disediakan sangat sedikit, peluang beasiswa di luar APBD juga kurang dimanfaatkan dengan baik oleh Pemerintah Daerah maupun ASN.

2. Terdapat beberapa faktor strategis internal dan eksternal dalam pengembangan kompetensi ASN Kabupaten Naganraya, S.E.bagai berikut.

\section{Faktor strategis internal}

1. Kekuatan (Strengths)

- Peraturan perundang-undangan

- Visi misi Bupati Naganraya

- Kewenangan

2. Kelemahan (weakness)

- Belum adanya Perbup tentang tugas belajar dan izin belajar 
- Terbatasnya anggaran pengembangan kompetensi manajerial ASN melalui pendidikan dan pelatihan

\section{Faktor strategis eksternal}

1. Peluang (opportunities)

- Adanya program beasiswa di luar APBD Naganraya

- Adanya sekolah tinggi di Kabupaten Naganraya

2. Ancaman (threats)

- Intervensi Politik dalam pengembangan kompetensi manajerial ASN

- Adanya mindset ASN yang menganggap tugas belajar di politisasi

3. Adapun strategi yang sebaiknya digunakan dalam pengembangan kompetensi ASN kabupaten Naganraya sebagai berikut.

\section{Isu sangat strategis}

a. Menyusun Perbup sebagai rujukan tugas belajar dan izin belajar baik anggaran yang menggunakan APBD maupun di luar APBD.

b. Membentuk satuan tugas percepatan pengembangan kompetensi manajerial ASN dalam pemanfaatan beasiswa tugas belajar di luar APBD.

c. Membangun kerja sama dengan sekolah tinggi yang ada di Kabupaten Naganraya.

\section{Isu cukup strategis}

a. Meningkatkan sosialisasi, dan transparansi serta kepastian pelayanan.

b. Mendorong ASN untuk izin belajar di sekolah tinggi yang ada di Kabupaten Naganraya.

c. Memanfaatkan dan memfasilitasi ASN dalam mengikuti beasiswa di luar APBD. d. Membangun komitmen bersama untuk bekerja secara profesional.

\section{SARAN}

1. Perlunya memperbanyak kesempatan untuk mengikuti pendidikan dan pelatihan serta memanfaatkan peluang beasiswa di luar APBD dengan maksimal dalam rangka Pengembangan Kompetensi Manajerial ASN Kabupaten Naganraya.

2. Perlunya memanfaatkan peraturan perundang-undangan dan kewenangan untuk menyusun Peraturan Bupati tentang Tugas Belajar dan Izin Belajar yang menjadi dasar hukum dalam pengembangan kompetensi baik dalam hal penambahan anggaran, SOP dalam penetapan peserta, dan memfasilitasi ASN untuk memanfaatkan beasiswa di luar APBD Kabupaten Naganraya.

3. Untuk melaksanakan strategi perlunya mengoordinasikan dalam hal penyusunan Peraturan Bupati tentang Tugas Belajar dan Izin Belajar serta bekerja sama untuk membentuk satuan tugas percepatan pengembangan kompetensi manajerial, dan meningkatkan kualitas pelayanan kepegawaian dalam pengembangan kompetensi manajerial ASN Kabupaten Naganraya.

\section{DAFTAR RUJUKAN}

Almasdi, Yunus Suit, 2006. Aspek Sikap Mental Dalam Manajemen Sumber Daya Manusia Indonesia, Jakarta: Ghalia Indonesia.

Ambar Teguh Sulistiyani dan Rosidah, 2003, Manajemen Sumber Daya Manusia. Yogyakarta: Graha Ilmu.

Arikunto, Suharsimi, 2013, Prosedur Penelitian, Rineka Cipta, Jakarta.

Budiarjo,Miriam.2003,Dasar-Dasar Politik. Jakarta: PT.Gramedia Pustaka Utama. 
Busro, Muhammad, 2018, Teori-Teori Manajemen Sumber Daya Manusia, Jakarta: Prenadamedia Group

Dharma, Surya. 2002. Manajemen Sumber daya Manusia: Paradigma Baru. Yogyakarta: Amara Books

Handoko, T. Hani. 2001. Manajemen Personalia dan Sumber Daya Manusia. Yogyakarta :BPFE

Hasibuan, Malayu. 2005. Manajemen Sumber Daya Manusia Jakarta: PT Bumi Aksara.

Hasibuan, Malayu. 2009. Manajemen Sumber Daya Manusia Jakarta: PT Bumi Aksara.

Irawan Soehartono 2011, Metode Penelitian Sosial Suatu Teknik Penelitian Bidang Kesejahteraan Sosial dan Ilmu Sosial Lainnya, Rosdakarya, Bandung.

Jhon W. Creswell, 2009.Research Design Qualitative, Quantitative and Mixed Methods Approaches.

Kadarisman, M. 2013. Manajemen Pengembangan sumber Daya Manusia.Jakarta: Rajawali Pers

Lexy Moleong,2013.Metode Penelitian Kualitatif, Rosdakarya Bandung.

Moeheriono. 2009. Pengukuran Kinerja Berbasis Kompetensi. Jakarta: Ghalia Indonesia

Mangkunegara, A.A. Anwar Prabu. 2010. Perencanaan dan Pengembangan Sumber Daya Manusia. Bandung: PT Refika Aditama

Nawawi, Hadari, 2012, Manajemen Stratejik Organisasi Nonprofit Bidang Pemerintahan, UGM Press, Yogyakarta.

Nazir, Moh., 2014, Metode Penelitian, Ghalia Indonesia, Bogor.

Ndraha, Taliziduhu.2011 Kybernologi (Ilmu Pemerintahan Baru) 1. Jakarta, Rineka Cipta

Notoatmodjo, Soekidjo. 2009. Manajemen Sumber Daya Manusia. Jakarta: Rineka Cipta

Priansa, Donni Junni. 2014. Perencanaan dan Pengembangan Sumber Daya Manusia. Bandung: Alfabeta

Rachmawati, Ike. 2008. Manajemen Sumber Daya Manusia,Yogyakarta: C.V Andi Offset
Rangkuti, Freddy, 2016, Teknik Membedah Kasus Bisnis Analisis SWOT, Gramedia Pustaka Utama

Rasyid, Muhammad Ryaas. 1997. Makna Pemerintahan Tinjauan dari Segi Etika dan Kepemimpinan. Jakarta: Yarsif Watampone

Robbins, P. Stephen. 2007. Perilaku Organisasi. Edisi 10. Terjemahan. Jakarta: PT Macanan Jaya Cemerlang

Rivai,Veithzal. 2009. Manajemen sumber Daya Manusia Untuk Perusahaan Dari Teori ke Praktik. Jakarta: Rajawali Pers

Simangunsong, Fernandes, 2016, Metodologi Penelitian Pemerintahan, Bandung: Alfabeta.

Soeprapto. 2000. Manajemen SDM. Yogyakarta: BPFE UGM

Sugiyono, 2014, Metode Penelitian Kuantitatif, Kualitatif dan R \& D, Bandung: Alfabeta.

Veithzal, Rivai. 2004, “Manajemen Sumber Daya Manusia Untuk Perusahaan, Cetakan Pertama, Jakarta: PT Raja Grafindo Persada

Wasistiono, Sadu dan Simangunsong, Fernandes, 2015, Metodologi Ilmu Pemerintahan (Edisi Revisi yang Diperluas), IPDN Press, Jatinangor.

Wasistiono, Sadu. 2001, Kapita Selekta Manajemen Pemerintahan Daerah. Bandung, Alqaprint.

Wibowo. 2014.Manajemen Kinerja. Jakarta: Rajawali Press

\section{Peraturan Perundang-Undangan}

Undang-Undang Republik Indonesia No. 5 Tahun 2014 tentang Aparatur Sipil Negara Sipil Negara

Undang-Undang Republik Indonesia No. 23 Tahun 2014 tentang Pemerintahan Daerah

Peraturan Pemerintah Republik Indonesia No. 11 Tahun 2017 tentang Manajemen Kepegawaian

Qanun Kabupaten Naganraya Noor 3 Tahun 2016 tentang Pembentukan dan Susunan Perangkat Daerah Kabupaten Naganraya 
Peraturan Bupati Naganraya No. 77 Tahun 2016 tentang Kedudukan, Susunan Organisasi, Tugas, Fungsi dan Tata Kerja Badan Kepegawaian dan Pengembangan Sumber Daya Manusia Kabupaten Naganraya

Rencana Strategis Badan Kepegawaian Dan Pengembangan Sumber Daya Manusia Kabupaten Naganraya Tahun 2017-2022

Laporan Tahunan BKPSDM Kabupaten Naganraya Tahun 2017 s.d. 2019

Surat Edaran MenPAN-RB No. 4 Tahun 2013 tentang Tugas Belajar dan Izin Belajar

Peraturan Kepala Lembaga Administrasi Negara No. 18 Tahun 2015 tentang Pedoman Penyelenggaraan Pendidikan dan Pelatihan Kepemimpinan Tingkat II

Peraturan Kepala Lembaga Administrasi Negara No. 19 Tahun 2015 tentang Pedoman Penyelenggaraan Pendidikan dan Pelatihan Kepemimpinan Tingkat III

Peraturan Kepala Lembaga Administrasi Negara No. 20 Tahun 2015 tentang Pedoman Penyelenggaraan Pendidikan dan Pelatihan Kepemimpinan Tingkat IV

Naganraya Dalam Angka 2020

\section{Sumber Lain}

I Ketut Dartha, "Pengaruh Pendidikan dan Pelatihan (Diklat) terhadap Kinerja Pegawai Negeri Sipil Pada Sekretariat Daerah Kota Malang", Jurnal Ekonomi MODERNISASI, Vol 6: No 2, (Juni 2010), hlm 140.

Setiadiputra Raden Y.P, "Urgensi Pemberian Pengembangan Kompetensi SDM Secara Berkesinambungan di Lingkungan Instansi Pemerintah" Jurnal SAWALA Vol 5 No 1 April 2017, hal. 18

Utang, Suwaryo, "Implementasi Kebijakan Otonomi Daerah (Studi Kasus tentang Kewenangan Dalam Aplikasi Otonomi Daerah Berdasarkan Undang-Undang No. 22 Tahun 1999 di Kabupaten Bandung)", Sosiohumaniora Vol 8 No 3 November 2006, hlm. 17

Z. Zaenal, "Grand Design Pengembangan Kompetensi Aparatur Sipil Negara Sipil Negara Dalam Mewujudkan Visi Reformasi Birokrasi", Jurnal Administrasi Publik Volume XII No. 2 Desember 2016, hal.107 